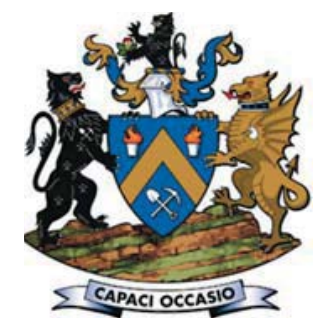

\title{
Microseismic events for slope stability analysis - a case study at an open pit mine
}

\author{
by X. Luo* , M. Salvoni ${ }^{\dagger}$, P. Dight ${ }^{\dagger}$, and J. Duan*
}

\section{Synopsis}

Slope instability is one of the major concerns in open pit mining. A significant collapse of the pit wall can result in injuries or fatalities, damage to mining equipment, interruptions to production, and potential loss of reserves. Properly interpreted microseismic data can be used to augment surface monitoring systems in identifying potential instability and the associated failure mode. A challenge for this microseismic application is that many seismic events associated with slope movements are weak and they hardly trigger a microseismic monitoring system that is set up to record an event in a trigger mode. A research project carried out at an open pit mine in Australia used both trigger mode and continuous mode to record microseismic events. The preliminary results have shown that the weak events are equally important as the strong seismic events for slope stability assessment, and they should not be ignored in microseismic monitoring for open pit mining.

Keywords open pit, slope stability, microseismics, weak seismic events, prediction.

\section{Introduction}

Maintaining slope stability is a major task for open pit mining and civil engineering. Microseismic monitoring techniques have been recognized as an efficient tool to map rock fracture network development for slope stability assessment (Hardy and Kimble, 1994; Lynch and Malovichko, 2006). Properly interpreted microseismic data can be used to augment surface monitoring systems in identifying potential instability and the associated failure mode. This technique has been used for identifying potential failure locations (Trifu, Shumila, and Leslie, 2008), estimating potential damage scales and unstable volume (Wesseloo and Sweby, 2008), and prediction of impending failures and improving understanding of how mining affects the pit stability (Lynch et al., 2005).

Microseismic monitoring techniques measure seismic signals generated from rock breakage or movement inside the open pit. As microseismic sensors can measure rock fracture events remotely, these techniques are capable of mapping the 4D pattern and dynamic development of rock fractures before any deformation on the slope surface can be observed.
A microseismic system used for open pit monitoring normally consists of a geophone network with a number of geophones installed in the ground, spaced at 100-200 m. In order to obtain the 4D pattern of seismicity, the seismic signals must be recorded by four or more geophone stations. The system is commonly operated in a trigger mode, based on a short-time averages (STA) and long-time averages (LTA) algorithm. When at least four stations experience a STA/LTA ratio greater than the set threshold, the system is triggered and the event is recorded. This approach was developed for underground mines, where there has been a focus on larger events leading to hazard identification and re-entry protocols (Mendecki, 1997).

However, near an open pit mine slope, the rock mass can be highly fractured because of blasting, destressing, and weathering. The fractured nature of the rock near surface may cause significant attenuation of the seismic waves. (Willenberg et al., 2002) and a small seismic event may not be strong enough to trigger four geophones.

Due to the weakness of the initiated seismic energy and fracture attenuation, many weak seismic events may only trigger one or two nearby geophones. It is possible for many weak events that are not recorded by the trigger mode to occur near the slope before ground movement can be observed. Weak seismic events are as important as strong seismic events for open pit stability assessment. However, there has been lack of investigations of these weak seismic events in previous microseismic monitoring projects at open pit mines.

* Geomechanics and Ground Control, CSIRO Energy, Australia.

+ Australian Centre for Geomechanics, the University of Western Australia, Australia.

(c) The Southern African Institute of Mining and Metallurgy, 2018. ISSN 2225-6253. This paper was first presented at the AfriRock 2017 International Symposium, 30 September -6 October 2017, Cape Town Convention Centre, Cape Town. 


\section{Microseismic events for slope stability analysis - a case study at an open pit mine}

An investigation of weak seismic events was carried out using a microseismic data-set that was continuously recorded at an open pit in Australia. The objectives of this project were to investigate the characteristics of the weak events and to explore the feasibility of using these events for the stability assessment of an open pit. In this paper, the preliminary results from this study are presented.

\section{Monitoring site and the microseismic system}

The Century mine is an open pit mine owned and operated by Minerals and Metals Group (MMG) Limited. It is located near Lawn Hill in North Queensland. Since mining in the southwest corner commenced, the area has represented an ongoing challenge for engineers on site, due to persistent unravelling on bedding planes and ground deformation. The pit wall is mainly developed in shales and it is characterized by the presence of two main structures, the Pandora's and Page Creek faults (Figure 1). Moreover, a massive block of carbonate breccia (CBX), covering approximately four benches, outcrops along Pandora's Fault. The pit wall has a total height of $300 \mathrm{~m}$ and an overall slope angle of $40^{\circ}$. In order to prevent further development of instability in the lower section of the wall during mining, a buttress was left in situ (approx. $28^{\circ}$ overall angle). More details on the instability history and geological/geotechnical settings of the area are discussed in Hendersonhall et al. (2010), Kurukuk and Sweeney (2012), and Salvoni et al. (2015).

As direct access to the pit wall was limited for the installation of traditional subsurface monitoring instrumentations (inclinometers, piezometers and/or extensometers), there were no indications on how extensively the rock mass was damaged behind the pit wall. For this reason, in 2013 MMG management decided to implement a microseismic monitoring system. The Australian Centre for Geomechanics (ACG) led the project, with the aim to assess any potential for a deep-seated failure development.

The microseismic monitoring system was provided by the Institute of Mine Seismology (IMS) and comprised 16 geophones, installed in four long (approx. $400 \mathrm{~m}$ ) inclined and two short (approx. $10 \mathrm{~m}$ ) vertical boreholes. Due to the limited access to the area and the pit geometry, navi-drilling behind the pit crest was the only option to get the instruments sufficiently close to the instability area. The technical specifications of the geophones and seismic instruments, data acquisition, and transmission equipment are discussed in Salvoni et al. (2015). The seismic events were recorded based both on a triggered scheme and in continuous mode. IMS personnel were in charge of manually processing the triggered data and made it available for the engineers on site within 10 minutes of an event. From December 2013 to June 2014, a collaborative project was also established between the ACG and CSIRO in order to conduct further investigations, looking at the data recorded in the continuous mode.

\section{Surface displacement survey and microseismicity}

Prior to the installation of the microseismic array, the instability of the southwest wall was monitored through a surface monitoring system. This comprised a geodetic prism network and a ground-based, real aperture radar. A review of the historical data-set from surface monitoring has indicated how surface deformations are related to the wet and dry seasonal cycle typical of this area, with the water acting as a triggering mechanism for movement (Figure 2). Rates of displacement following rainfall events can exceed $10 \mathrm{~mm} / \mathrm{d}$, with cumulative displacements of several metres. The CBX block appeared to be involved in an active-passive wedge mechanism, being rotated and pushed out from the wall (Salvoni et al., 2015). During the dry season, movements maintain steady displacements of approximately $1 \mathrm{~mm} / \mathrm{d}$. However, Salvoni et al., (2015) stressed that inferring rock mass behaviour at depth from surface deformations may be misleading. In fact, after exposure the shales tend to rapidly break up and deteriorate due to the high clay mineral content (montmorillonite) and the sulphide mineral pyrite $\left(\mathrm{FeS}_{2}\right)$. Several authors emphasized how in shales of low durability, mechanisms of slaking, erosion, and surface creep are dominant (Franklin, 1981; Marques, Vargas, and Antunes, 2005; Alonso and Pineda, 2006). This case study provided us with a good opportunity to compare results obtained from the microseismic and surface monitoring systems.

From the middle of February 2014, after several days of rainfall, an extended reactivation of the instability in the upper section of the pit wall and in the CBX block was
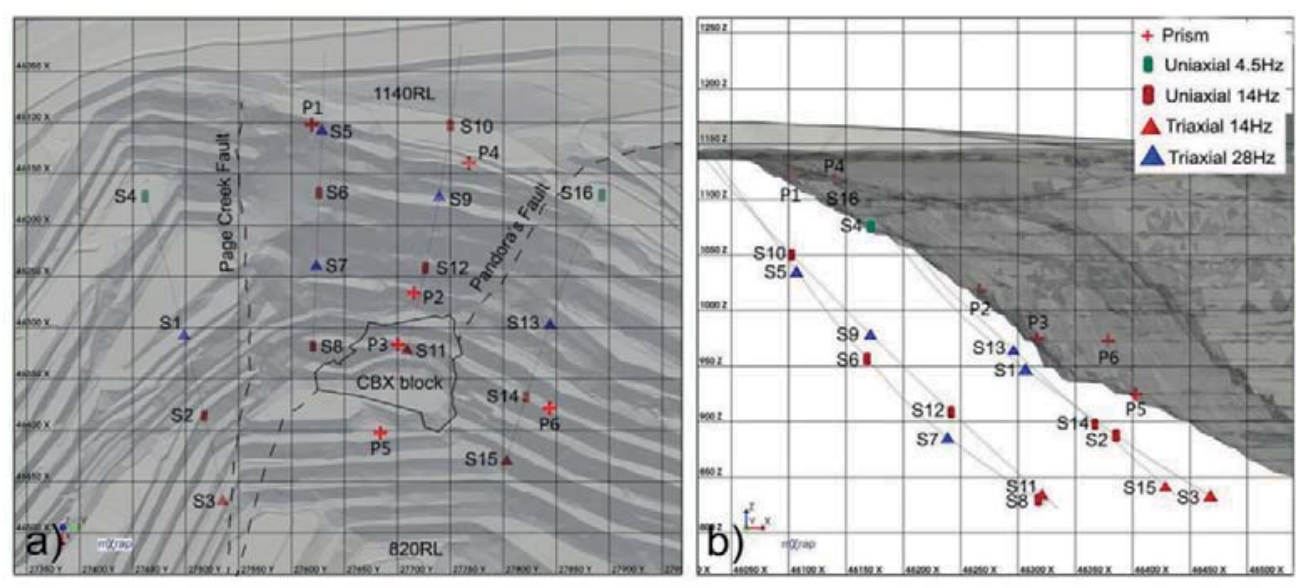

Figure 1-Microseismic array configuration showing location and type of geophones (S1-S16) installed. P1-P5 are the locations of the prism survey points. Plan view (a) and sectional view (b) 


\section{Microseismic events for slope stability analysis - a case study at an open pit mine}
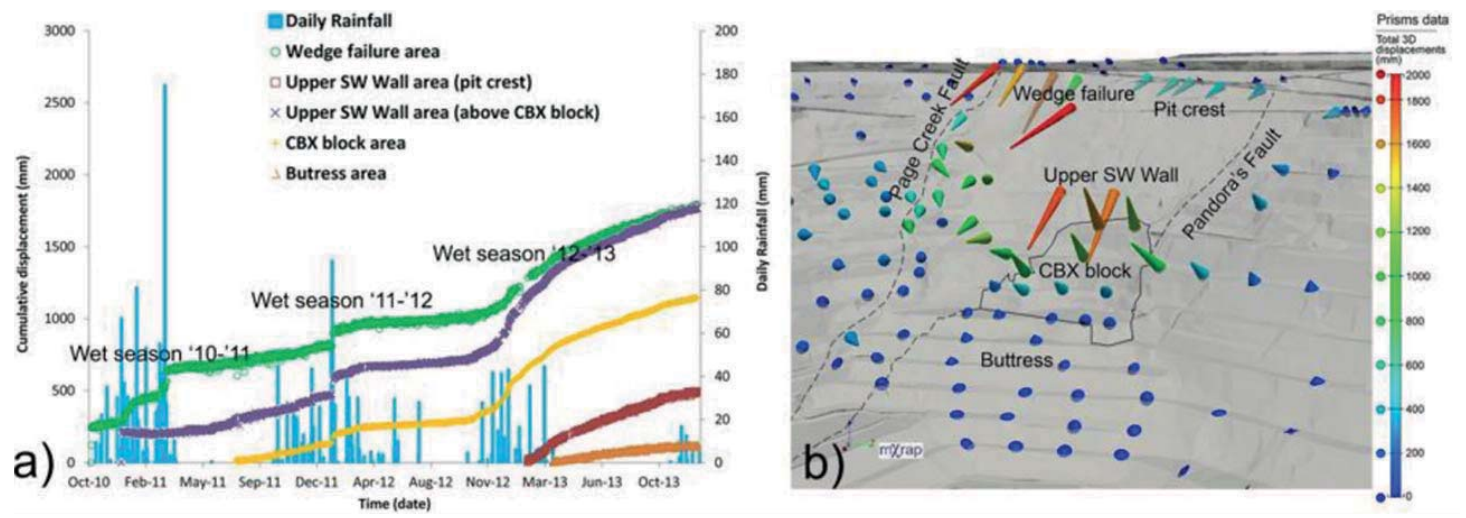

Figure 2-Ground displacements recorded by the prism monitoring and daily rainfall between October 2010 and January 2014 in different areas of the slope. (a) 3D view showing the displacement vectors for the same time period and coloured by total cumulative displacement, (b) the microseismic monitoring project was started in October 2013

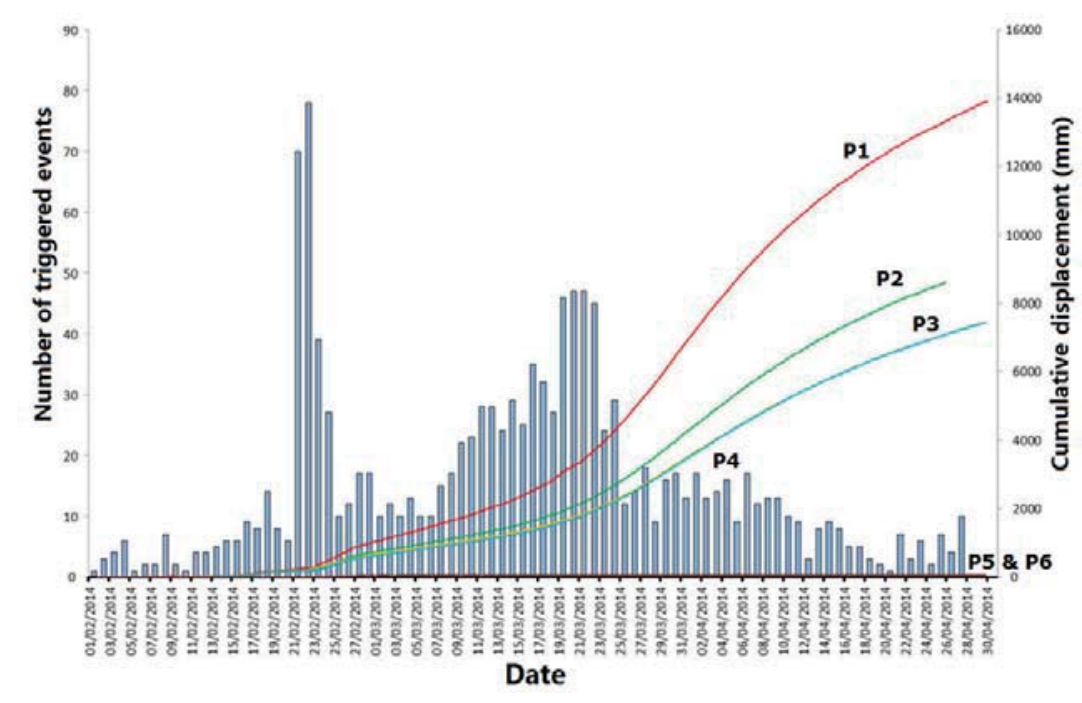

Figure 3-Pit surface displacements observed at the prism points (P1-P6) and the seismicity associated with 1305 triggered events, from 1 February to 30 April 2014

observed, with total cumulative displacements over $10 \mathrm{~m}$ in only 3 months. No major deformations were experienced in the lower section of the wall (buttress area). At the same time, seismic activity rates increased sharply, with a total of 1241 events recorded between February and April using the triggered database (Figure 3). In particular, on 23 and 24 February a spike in seismicity rate was observed related to a small failure that occurred in upper section of Page Creek Fault. Following this, a general rise of seismicity was observed behind the pit wall, with activity concentrated mainly in the upper section of the slope and the base of the CBX block (Figure 4).

\section{Analysis of weak events and discussion}

In the continuous microseismic data-set, many weak seismic events were found to be recorded by only one geophone station. Figure 5 shows a typical weak event recorded only by geophone S5. This event occurred at 11:47 am on 25 February, when the southwest wall started to move. Figure 6 shows the zoom-in waveforms and signal frequency contents of this event, on the three geophone components of S5.
Figures 7 and 8 show another weak event recorded by geophone 59 , at 18:40 on the same day.

The data processing for the weak events was conducted manually on the continuous data-set that does not contain the reported triggered events. As the continuous data-set is huge, at the first stage we concentrated our effort on the data for two special days - February 10 when the slope was in a stable condition, and February 25 when obvious surface movement was observed.

The amplitudes of the weak events have been found to be in the range of $10^{-7} \mathrm{~m} / \mathrm{s}$, whereas the amplitudes of strong signals are above $10-6 \mathrm{~m} / \mathrm{s}$. The dominant frequency of the weak signals is in the range from $110-150 \mathrm{~Hz}$, much higher than that of the strong events showing $30-60 \mathrm{~Hz}$. The smaller amplitude and higher frequency may imply that a weak event is associated with a brittle rock fracturing event or a sudden movement of a structure at a small scale near the slope and close to the geophone location.

The identification of the weak events was carried out on the events that were recorded by only one geophone station (Figures 5 and 7, for example). On these two days, geophone 


\section{Microseismic events for slope stability analysis - a case study at an open pit mine}

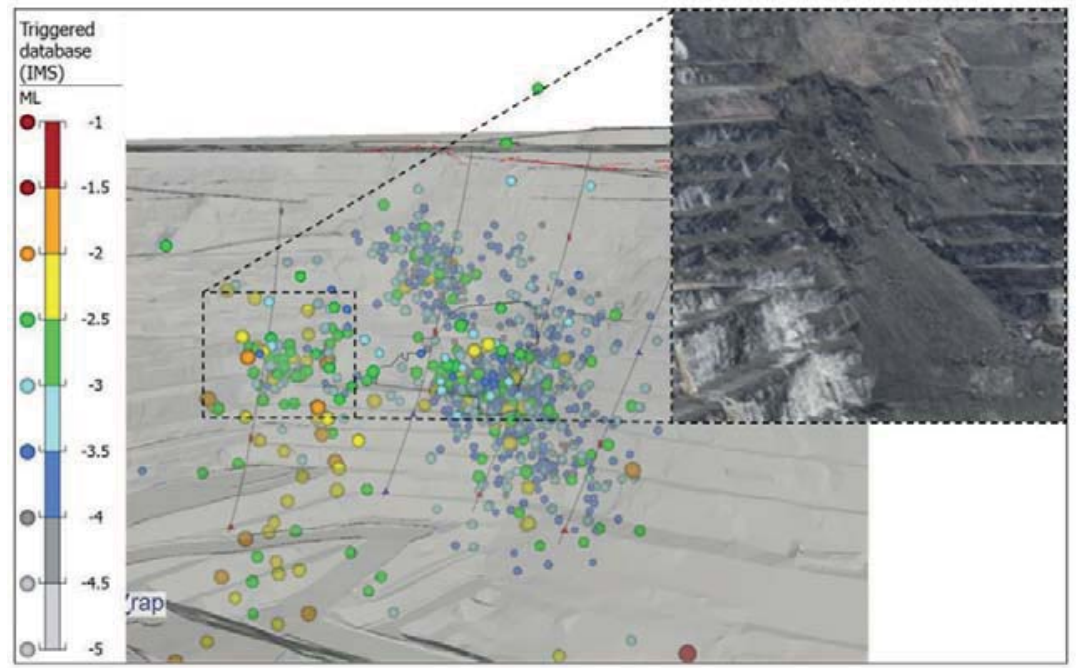

Figure 4-Seismic events located by IMS from 11 February to 31 April 2014; events are coloured and sized based on local magnitude (ML)

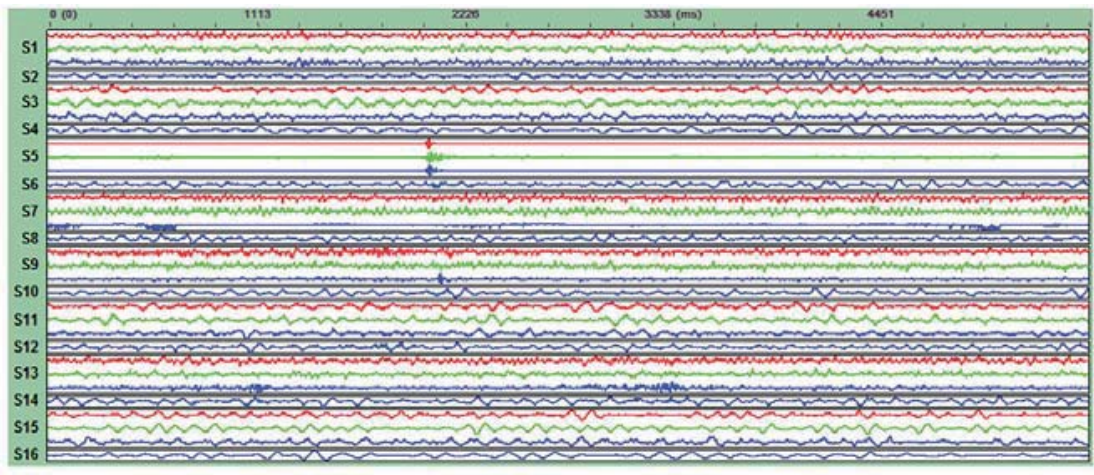

Figure 5-A typical weak event recorded by the 3-component geophone, S5. For a 3-component geophone, the red, green, and blue traces are the north, east, and vertical components, respectively. The waveform of a single-component geophone is shown in blue. Each of the seismic waveforms is normalized to its own maximum amplitude

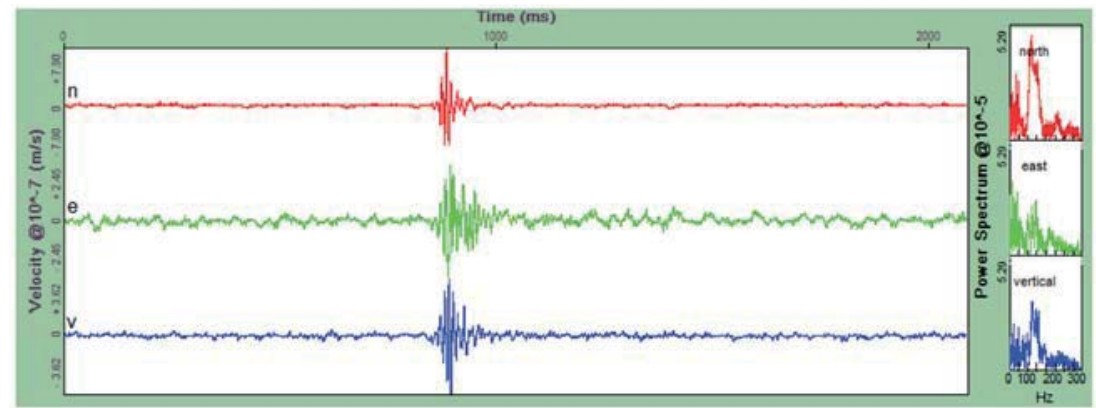

Figure 6-A zoom-in on the seismic waveforms of the event recorded by S5 and shown in Figure 3. The frequency contents associated with the seismic signals are displayed on the right

S16 did not work properly and it was excluded from the data processing. The rest of the geophones (S1-S15) were in good working condition.

The number of the weak events identified on the two days is summarized in Table I. It is evident that there is a big difference in seismicity on these two days. On February 10 when the ground was stable, only seven events were observed. However, on the day that the slope started to move, 1768 events occurred. As a seismic event is associated with a rock fracturing or a defect weakening event inside the pit wall, this increase in seismicity may have indicated a significant deterioration of the ground in the vicinity of the geophones that recorded high seismic activity rates.

Compared to the weak events, there were no triggered events 


\section{Microseismic events for slope stability analysis - a case study at an open pit mine}

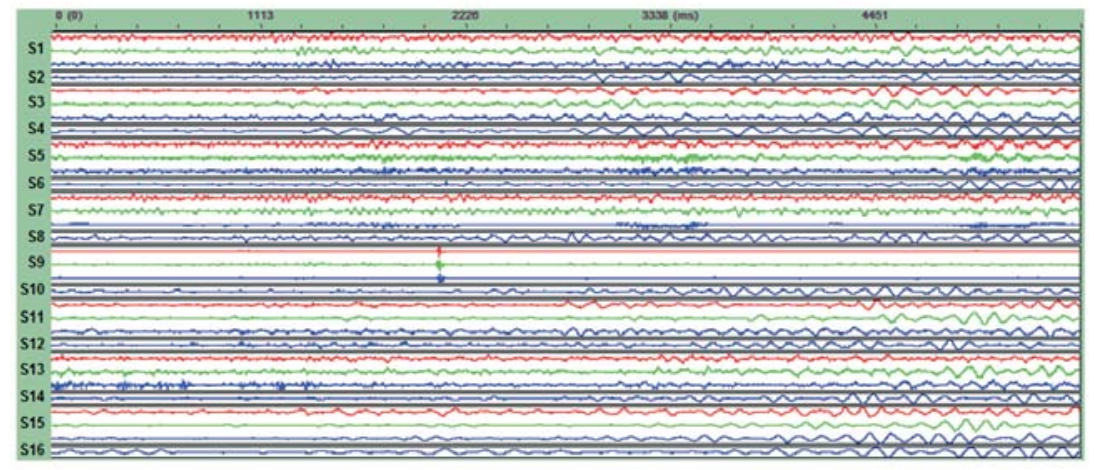

Figure 7-A weak event recorded by the 3-component geophone S9

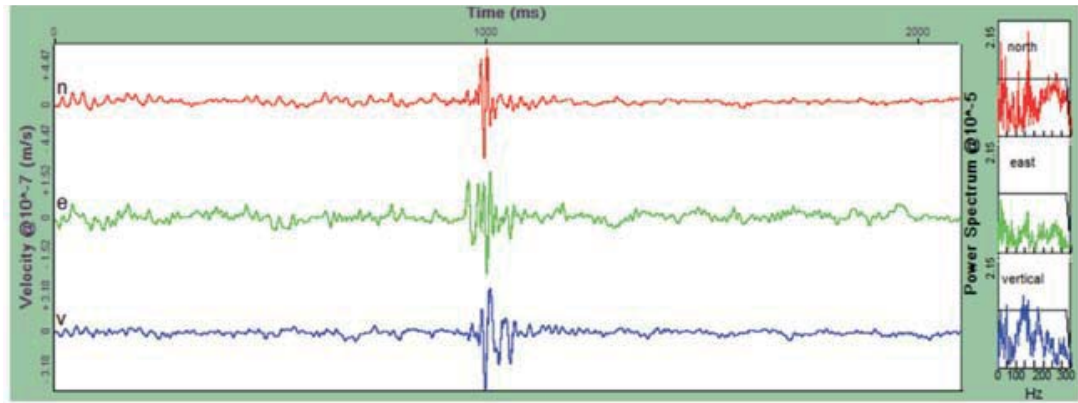

Figure 8-A zoom-in on the seismic waveforms of the event recorded by S9 and shown in Figure 5. The frequency contents associated with the seismic signals are displayed on the right

within $20 \mathrm{~m}$ of the sensors. This means that close to the sensors we have only weak events.

An interesting fact shown in Table I is that seismic sensors S5, S9, and S10 recorded more events than the others. These geophones are located close to the prism points P1, P2, and P4, where noticeable ground movement was measured (see Figure 3). Sensor S13 also recorded a large number of events, but no prism point was installed close by to enable comparison of the results. However, significant surface movements were visually observed after 25 February near S13.

The different seismic activity rates at different geophone stations provided good information for estimating ground weakening locations. Figure 9 shows the locations of the weak seismicity recorded by individual geophones and strong events recorded by the trigger mode on 10 and 25 February. On these two days, the strong events are sparsely distributed and it is difficult to use these locations to infer the location of potential ground movement. However, the different seismic activity rates at different geophone locations indicate different scales of ground failures near the geophone stations, from which the location of potential ground movement can be inferred.

\section{Conclusions}

This study has shown the value of continuous data in order to detect weak events and have a better comprehension of the rock mass damage close to the sensor locations. It is suggested that weak seismic events can be as important as strong seismic events for slope stability assessment and they should not be ignored in a microseismic monitoring project.
Table I

The number of the weak seismic events recorded on the day of no ground movement and the day when the ground started moving

\begin{tabular}{|c|c|c|}
\hline \multirow{2}{*}{$\begin{array}{l}\text { Geophone } \\
\text { station }\end{array}$} & \multicolumn{2}{|c|}{ Number of weak seismic events } \\
\hline & $\begin{array}{c}\text { Stable ground } \\
\text { (10 February 2014) }\end{array}$ & $\begin{array}{c}\text { Moving ground } \\
\text { (25 February 2014) }\end{array}$ \\
\hline S1 & 1 & 14 \\
\hline $\mathrm{S} 2$ & 0 & 2 \\
\hline S3 & 0 & 0 \\
\hline $\mathrm{S4}$ & 0 & 0 \\
\hline$\overline{\mathrm{S} 5}$ & 3 & 139 \\
\hline$\overline{\mathrm{S} 6}$ & 0 & 14 \\
\hline$\overline{\mathrm{S} 7}$ & 0 & 2 \\
\hline $\mathrm{S8}$ & 0 & 0 \\
\hline S9 & 0 & 44 \\
\hline $\mathrm{S} 10$ & 0 & 884 \\
\hline $\mathrm{S} 11$ & 0 & 1 \\
\hline $\mathrm{S} 12$ & 1 & 7 \\
\hline $\mathrm{S} 13$ & 1 & 638 \\
\hline$\overline{\mathrm{S} 14}$ & 0 & 18 \\
\hline $\mathrm{S} 15$ & 1 & 5 \\
\hline$\overline{\mathrm{S} 16}$ & \multicolumn{2}{|c|}{ Not in working condition } \\
\hline Total & 7 & 1768 \\
\hline
\end{tabular}

The design of a microseismic network for slope stability monitoring should consider capturing both the strong and weak events, using both triggered and continuous recording modes. 


\section{Microseismic events for slope stability analysis - a case study at an open pit mine}

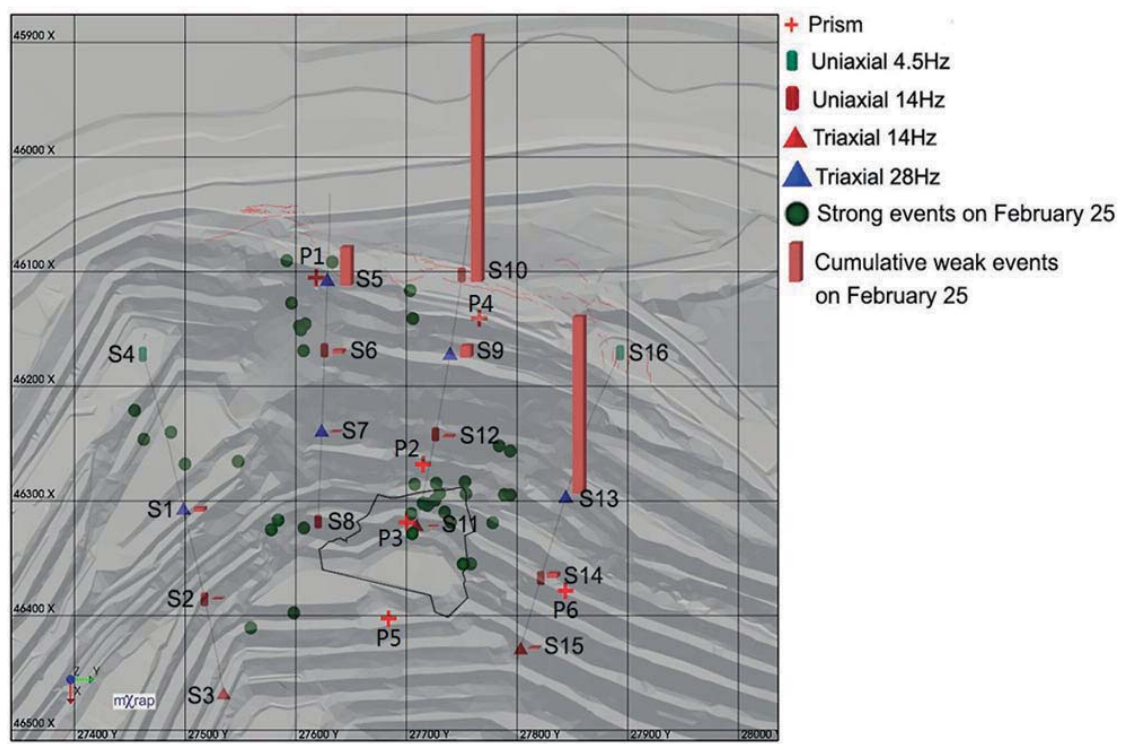

Figure 9-Locations of weak seismicity (red bars) and triggered strong events (colour circles) that were recorded on 10 and 25 February 2014 . The seismicity on 10 February is very minor and the red bars actually show seismicity on 25 February

Only results from the analysis of the weak seismic events for two particular days were presented. Analysis of the data recorded on other days is still in progress, in order to obtain the whole picture about the characteristics of the weak events against the surface dislocations. Several issues will be addressed in our following research:

> The characteristics of seismic signals of the weak events associated with different stages of ground movement

> The relationship between the weak and triggered events

> Interpretation of the source mechanisms of the weak events and evaluation of event location methods using a single station, for estimating the weak events locations

> Automatic and reliable identification and selection of the weak events.

\section{Acknowledgements}

The authors are deeply grateful to MMG Limited for funding the project and allowing access and providing logistic support to the study area. We thank Gerrit Olivier and Stephen Myer of IMS for providing the SEGY continuous data-set for processing and for their patience in explanation of their methods for seismic source location and energy estimation. This project is mainly supported by ACG. CSIRO provided inkind support to this study.

\section{References}

Alonso, E.E. and PinedA, J.A. 2006. Weathering and degradation of shales: experimental observations and models of degradation. Proceedings of the VI South American Congress of Rock Mechanics, Cartagena de Indias, Colômbia, 8-13 October 2006. International Society for Rock Mechanics, Lisbon, Portugal.

FrankLIN, J.A. 1981. A shale rating system and tentative applications to shale performance. Transportation Research Record, vol. 790. pp. 2-12.

HARDY, H.R. and KIMBLE, E.J. 1991. Application of high-frequency AE/MS techniques to rock slope monitoring. Proceedings of the Fifth Conference on Acoustic Emission/Microseismic Activity in Geologic Structures and Materials, Pennsylvania State University, 11-13. June 1991. Hardy, H.R. (ed.). Trans Tech, Clausthal-Zellerfeld, Germany. pp. 457-477.

Hendersonhall, B.D., Lucas, D., KerR, N., and Pennisi, C. 2010. Practical management of progressive large failures at Minerals and Metals Group Century Mine. Proceedings of the Seventh Large Open Pit Mining Conference, Perth, Australia. Australasian Institute of Mining and Metallurgy, Melbourne.

KuRUKuk, N. and SwEENEY, E. 2012. Slope stability assessment Century. Proceedings of the 9th Australia - New Zealand Young Geotechnical Professionals Conference, Melbourne, Australia, 11-14 July 2012. Australian Geomechanics Society.

Lynch, R.A., Wuite, R., Smith, B.S., and Cichowicz, A. 2005. Microseismic monitoring of open pit slopes. Proceedings of the 6th International Symposium on Rockburst and Seismicity in Mines, 9-11 March 2005. Potvin, Y. and Hudyma M. (eds.). Australian Centre for Geomechanics, Perth. pp. 581-592.

LyNCH, R.A. and MALovichKo, D.A. 2006. Seismology and slope stability in open pit mines. Proceedings of the International Symposium on Stability of Rock Slopes in Open Pit Mining and Civil Engineering, Cape Town. Southern Africa Institute of Mining and Metallurgy, Johannesburg. pp. 375-390.

MarQues, E.A.G., Vargas JR, E.D.A., and Antunes, F.S. 2005. A study of the durability of some shales, mudrocks and siltstones from Brazil. Geotechnical and Geological Engineering, vol. 23. pp. 321-348.

Mendecki, A. J. 1997. Seismic Monitoring in Mines. Chapman and Hall.

SALvoni, M. and Dight, P. 2016. Rock damage assessment in a large unstable slope from microseismic monitoring-MMG Century mine (Queensland, Australia) case study. Engineering Geology, 2016.

Trifu, C-I., Shumila, V., and Leslie, I. 2008. Application of joint seismic event location techniques at Chuquicamata open pit mine, Chile. Massmin 2008 : Proceedings of the 5th International Conference and Exhibition on Mass Mining, Luleå, Sweden, 9-11 June, 2008. Schunnesson, H. and Nordlund, E. (eds). Luleå University of Technology. pp. 943-952.

Willenberg, H., Silllmann, T., Eberhardt, E., Evans, K., Loew, S., and Maurer, H.R. 2002. Multidisciplinary monitoring of progressive failure processes in brittle rock slopes - concepts and system desig. Proceedings of the 1 st European Conference on Landslides, Prague, Czech Republic, 24-26 June, 2002. Rybar, J., Stemberk, J., and Wagner, P. (eds.). CRC Press. pp. 477-483. 